\title{
Valorizando a cultura Guarani-kaiowá \\ através do ensino do espaço e do tempo
}

\author{
Valuing the Guarani-Kaiowá culture \\ through space and time teaching
}

Rosemeire Aparecida Nunes Oliveira ${ }^{1}$. Fernando Cesar Ferreira ${ }^{1}$

\begin{abstract}
Resumo: Este trabalho apresenta os resultados de uma intervenção didática, realizada por uma professora de física, envolvendo os conceitos de tempo e espaço para alunos indígenas de uma aldeia em Mato Grosso do Sul. Trata-se de pesquisa qualitativa de caráter exploratório. O corpus de análise é formado por dois conjuntos de dados: pré-teste envolvendo a noção de espaço e tempo dos alunos indígenas, e uma atividade sobre estratégias de medição de tempo e espaço. A coleta de dados foi feita durante as aulas de física para uma turma de 13 alunos, com idades variando entre 18 e 29 anos. Foi possível observar que medições de espaço e tempo através de estratégias tradicionais ainda estão presentes, apesar de muitos indígenas não valorizarem estes conhecimentos. Todo conhecimento tradicional que possa ser trazido para reflexão na escola, junto com o conhecimento científico, contribui para uma compreensão ampliada e ressignificada desses conhecimentos para os alunos indígenas.
\end{abstract}

Palavras-chave: Educação indígena. Ensino de física. Conhecimento tradicional indígena.

\begin{abstract}
This paper presents the results of a didactic intervention, carried out by a physics teacher, involving the concepts of time and space for indigenous students of Mato Grosso do Sul State, in Brazil. It is a qualitative research in an exploratory approach. The analysis' corpus consists of two sets of data: a) a pre-test involving the notion of space and time of the indigenous students and b) an activity on time and space measurement strategies. Data collection was taken during physics classes, with a sample of 13 students, ranging in age from 18 to 29 years. It was observed that measurements of space and time through traditional strategies are still present, although many indigenous people do not value this knowledge. All traditional knowledge that can be brought into thinking at school, along with scientific knowledge, contribute to a broader understanding and rethinking about these meanings for indigenous students.
\end{abstract}

Keywords: Physics teaching. Indigenous education. Indigenous traditional knowledge.

\footnotetext{
${ }^{1}$ Universidade Federal da Grande Dourados (UFGD), Faculdade de Ciências Exatas e Tecnologia, Dourados, MS, Brasil. E-mail: <rosemeirefisica@hotmail.com>.
} 


\section{Introdução}

A história da educação para os povos indígenas, por não indígenas, iniciou-se no período colonial, quando os jesuítas foram convidados pelos colonizadores para proporcionar educação religiosa. Esta abertura para um modelo de educação de uma cultura dominante, preocupada em impor valores e preconceitos, contribuiu para a construção de relações de descaso com os indígenas. De acordo com Meliá (1979, p. 9):

O processo educativo nas sociedades indígenas apresenta diferenças tais, com respeito ao que se dá na chamada educação "nacional", que às vezes se tem concluído que não existe educação indígena. Em outros, pressupõese que os índios não têm educação, porque não têm "a nossa educação".

A metodologia empregada para a educação indígena foi um simulacro do modelo de educação europeu, pois os portugueses não acreditavam que os indígenas possuíssem algum tipo de capacidade para a aprendizagem escolar. Certo é que, historicamente, a escola foi utilizada como instrumento do estado para submeter e integrar os povos indígenas. Assim, os diferentes povos deveriam abandonar as suas culturas, consideradas "primitivas", e aceitar como legítimas e verdadeiras as ideias e práticas da sociedade dominante.

Porém, a Guerra do Paraguai mostrou que os indígenas tinham uma forma própria de educação. A grande participação indígena neste evento deveu-se, em parte, aos conhecimentos geográficos que possuíam e que possibilitaram maior movimentação das tropas brasileiras no combate contra os paraguaios. De acordo com Vargas (2003, p. 52):

A contribuição desses índios estava além de sua presença física: eram eles também os responsáveis pelas informações que chegavam até o exército brasileiro, sua habilidade em reconhecer localidades e de espionar foi preciosa para o sucesso desse exército contra os paraguaios. Contudo, os índios não eram armados, não tinham adquirido o direito de possuírem armas como os demais soldados.

Antes da chegada dos europeus os indígenas já possuíam formas próprias de educação e produção de conhecimentos sobre agricultura, caça, pesca, medicina e geografia, entre outros. Com o contato entre indígenas e não indígenas, estes conhecimentos foram largamente utilizados em favor destes últimos. Hoje, paradoxalmente, acontece o inverso, são os indígenas que precisam adquirir os conhecimentos da sociedade não indígena para se tornarem integrantes dessa sociedade.

A escola surge neste contexto como entidade capaz de contribuir para a preservação da cultura indígena ante o choque com a sociedade não indígena. A Constituição de 1988, o Referencial Curricular Nacional para a Escola Indígena (RCNEI) (BRASIL, 1998) e os movimentos indígenas defendem que a educação voltada para os povos indígenas deve assumir uma postura que destaque suas especificidades. Neste sentido, Ângelo (2003, p. 108) afirma que: 
Com a inserção das escolas indígenas no sistema de ensino do país, como modalidade de ensino e a criação da categoria escola indígena, difere a escola indígena de outras escolas existentes no sistema, e obriga as instituições mantenedoras a se organizarem, a aprender a lidar com o novo contexto social da diversidade cultural, a prover novos instrumentos democráticos que garantam o atendimento dos direitos de cidadania.

Portanto, o ensino para alunos indígenas mostra-se com duplicidade de funções: revitalizar a cultura tradicional e tornar o indígena capaz de viver numa sociedade diferente da sua, em geral longe daquilo que o identifica como índio, a língua e a cultura, e sem que seus direitos sejam desrespeitados e suas ações desconsideradas.

$\mathrm{Na}$ educação tradicional indígena o ensino é um só para tudo, assim, muitos dos conteúdos ensinados em física, por exemplo, estão diretamente relacionados com questões da natureza. Já no ensino regular a física é entendida como corpo de conhecimento à parte e, por isso, costuma-se fazer algumas exigências para seu ensino: pré-requisitos, conhecimento matemático, entre outros. Já a física, como ciência experimental, tem uma forma particular de explicar o mundo real: experimentação, registro rigoroso de dados, hipóteses de trabalho.

A partir destas considerações é feito o recorte para este trabalho: observar a prática do ensino dos conceitos de tempo e espaço da física para um grupo específico de indígenas, alunos do Projovem Campo - Saberes da Terra.

O Projovem Campo - Saberes da Terra é um programa coordenado em nível nacional pela Secretaria de Educação Continuada, Alfabetização e Diversidade (SECAD), do Ministério da Educação (MEC) com o objetivo de garantir o direito de pessoas residentes na zona rural a uma educação digna e de qualidade, adequando-se tanto às suas necessidades imediatas, quanto à questão da pluralidade, seja ela de gênero, étnico-racial, cultural, geracional, política, econômica, territorial e produtiva, entre outras.

O projeto está orientado de acordo com o eixo curricular articulador Agricultura Familiar e Sustentabilidade, por sua vez ligado a vários eixos temáticos, entre os quais o de Ciências da Natureza e Linguagem Matemática. Neste último são apresentados os seguintes conteúdos: noções de astronomia; matéria e energia e a introdução ao estudo da física.

Um dos desafios para o ensino dos conceitos de tempo e espaço é que na grade curricular do ensino das Ciências da Natureza eles aparecem como entes separados e na educação indígena eles estão relacionados ao meio em que o indivíduo vive e não podem ser separados, não se pensa neles como conceitos separados.

\section{Os conceitos de espaço e tempo para o aluno indígena}

Esta pesquisa teve sua origem nos questionamentos sobre a percepção que os alunos indígenas participantes do Projovem Campo - Saberes da Terra têm sobre dois conceitos da física: tempo e espaço. Isso gerou duas perguntas: qual a noção de espaço e tempo que possuem e como, historicamente, construíram tal conhecimento? Quão próximo ou distante esse conhecimento está do que é aceito pela física? 
Fez-se necessário, então, escolher um referencial metodológico que permitisse organizar essas questões em um plano de trabalho, pois, de acordo com Luna (1988, p. 74), “o referencial teórico de um pesquisador é um filtro pelo qual ele enxerga a realidade, sugerindo perguntas e indicando possibilidades". A análise das práticas direcionadas para o conhecimento de tempo e espaço possibilitou a análise da ementa da disciplina para a educação escolar indígena. Esperase que tal análise contribua para o ensino nas escolas indígenas que estão inseridas na Reserva Indígena de Dourados (RID):

A educação escolar indígena pode ser definida como uma conquista pelo reconhecimento de que o Brasil é uma nação constituída por muitos povos, de diferentes etnias, com história, saberes, culturas e línguas próprias. Além de mostrar também o reconhecimento da existência de um grande número de povos indígenas no país, que constituíram, ao longo de sua história, suas organizações sociais, seus saberes e processos próprios de aprendizagem. (SECRETARIA MUNICIPAL DE EDUCAÇÃO, 2011, p. 18)

Os sujeitos da pesquisa são estudantes indígenas da aldeia Bororó, que buscam concluir o ensino fundamental com práticas em agricultura familiar. A turma é composta de jovens de diferentes faixas etárias (de 18 a 29 anos) das etnias Kaiowá e Guarani.

O diálogo entre educandos e educador se deu, por um lado, através da cultura indígena e dos conhecimentos tradicionais e, por outro, por meio da disciplina de Ciências da Natureza, com ênfase em física. Foi possível, então, observar diferentes conhecimentos em ação, principalmente no que se refere às ciências. Esta aproximação foi o aporte para a construção deste estudo, ou seja, por meio do contato direto entre grupos de diferentes culturas foi possível imergir com o novo desconhecido. Pois, segundo Martins (2004), trata-se de um mergulho na vida desses indivíduos. Nesse contato é necessário mais que uma simples aproximação, é preciso uma troca de confiança:

Esse mergulho na vida do grupo e em culturas às quais o pesquisador não pertence depende de que ele convença o outro da necessidade de sua presença e da importância de sua pesquisa. Para que a pesquisa se realize é necessário que o pesquisado aceite o pesquisador, disponha-se a falar sobre a sua vida, introduza o pesquisador no seu grupo e dê-lhe liberdade de observação. (MARTINS, 2004, p. 294)

Para o autor, este participar da vida do outro, dentro deste modelo de pesquisa, faz-se necessário já que a intenção é relembrar situações pertinentes ao momento e ao tema proposto, através da qual não só o participante revive como também o pesquisador se insere nesta contextualização por meio do que lhe é contado. Essa participação entende-se como uma colaboração mútua entre pesquisador e pesquisado, o que pode ser confirmado por Ibiapina, quando relata que:

[...] a colaboração implica em negociação dos conflitos que são inerentes ao processo de ensino e aprendizagem, representando formas de superação do 
já apreendido, visto que favorece a tomada de decisões democráticas, ação comum e a comunicação entre pesquisadores e professores [...] a pesquisa -ação somente pode ser considerada emancipatória quando é colaborativa. (IBIAPINA, 2008, p. 17)

Ibiapina (2008) sugere que todo conhecimento está permeado de conflitos, os quais, por sua vez, têm intrínseca forma de superações que beneficiarão a escolha de decisões que satisfaça a todos, direcionando-as a uma ação comum cuja comunicação seja um elo entre pesquisador e pesquisado, desta maneira será possível afirmar que se trata, então, de uma pesquisa-ação colaborativa.

A maior indagação sobre a temática aqui abordada está ligada a questões relacionadas ao conhecimento empírico que os alunos indígenas possuem a respeito do conceito de tempo e espaço. De maneira que tais conhecimentos, antes encontrados na transferência cultural de pai para filho, passem a fazer parte, em algum nível, do ensino oferecido pelas escolas indígenas. Este fato pode ser confirmado por Ibiapina (2008), quando discorre sobre a definição de pesquisa colaborativa:

A pesquisa colaborativa é prática que se volta para a resolução dos problemas sociais, especialmente aqueles vivenciados na escola, contribuindo com a disseminação de atitudes que motivam a coprodução de conhecimentos voltados para a mudança da cultura escolar e para o desenvolvimento profissional dos professores. (IBIAPINA, 2008, p. 23)

Por serem de cultura distinta do não índio e por estarem vivenciando inúmeros problemas sociais, principalmente no que se refere à educação regular, percebe-se uma tendência generalizada ao abandono de práticas ancestrais, levando a uma perda das tradições culturais e da identidade. Assim, passam a conviver com frequentes conflitos, em que o conhecimento adquirido através de experiências de vida nem sempre são valorizados pela sociedade não indígena, quanto o são para o fortalecimento do grupo indígena em que está inserido.

Os sujeitos da pesquisa são das etnias Kaiowá e Guarani, matriculados na extensão do Projovem Campo - Saberes da Terra, desenvolvido na Escola Municipal Indígena Agustinho. O Projovem é um programa desenvolvido pela Coordenação-Geral de Educação do Campo, Diretoria de Educação para Diversidade, vinculada à Secretaria de Educação Continuada, Alfabetização e Diversidade do Ministério da Educação (MEC/SECAD) com o objetivo de promover a escolarização com qualificação social e profissional do jovem agricultor no Brasil. As aulas tiveram início em março de 2010 e encerraram em dezembro de 2011.

Foram matriculados 35 alunos da aldeia Bororó, situada no Município de Dourados-MS. Desses 35 alunos, 13 participaram da pesquisa, sendo 4 homens e 9 mulheres, com idades variando entre 18 e 29 anos. Para manter o anonimato os participantes são designados por números. Os dados foram coletados a partir das atividades realizadas com os participantes durante as aulas de ciências. Nestas foram observadas e registradas as concepções que pais e avós dos alunos, além de outros anciões da comunidade, possuem dos ensinamentos baseados na cultura, de forma que seja explicitada a maneira pela qual constroem os conceitos de espaço e tempo na perspectiva indígena. 
As atividades foram divididas em dois grupos: (1) pré-teste: os alunos são convidados a exporem seus conhecimentos empíricos sobre espaço e tempo na forma de textos e desenhos, entre outros; (2) atividade de ensino: os alunos discutem, com a mediação do professor, uma prática sobre evolução temporal e espacial da sombra de uma vareta, a partir da luz do Sol, dentro de um círculo.

Das atividades mencionadas surgem os elementos que são considerados essenciais pelos alunos para seu dia a dia como, por exemplo, tirar a metragem na construção de uma casa ou fazer medições menores utilizando os passos, como no plantio de mandioca e de milho, e o uso da sombra projetada pelo Sol em árvores e casas na determinação da hora do dia. Outro elemento descrito pelos alunos é a identificação do melhor período para caça, pesca e plantio da roça a partir das fases da Lua e das estações do ano.

\section{Metodologia e análise de dados}

Trata-se de pesquisa qualitativa (FLICK, 2009a, 2009b; LÜDKE; ANDRÉ, 2008), de caráter exploratório (OLIVEIRA, 2007; TRIVIÑOS, 1987). De acordo com Oliveira (2007, p. 65):

[...] este tipo de pesquisa desenvolve estudos que dão uma visão geral do fato ou fenômeno estudado. Em regra geral, um estudo exploratório é realizado quando o tema escolhido é pouco explorado, sendo difícil a formulação e operacionalização de hipóteses. Muitas vezes, esse tipo de estudo se constitui em um primeiro passo para a realização de uma pesquisa mais aprofundada.

O corpus de análise é formado por dois conjuntos de dados: (a) um pré-teste envolvendo a noção de espaço e tempo dos alunos indígenas e (b) uma atividade prática sobre estratégias de medição de tempo e espaço.

\section{Primeira Atividade: pré-teste}

No dia 15 de dezembro de 2010 foi dito aos alunos do Projovem Campo - Saberes da Terra que uma atividade diferenciada seria realizada na próxima aula de Ciências. Foram informados que a atividade seria sobre espaço e tempo. Os alunos se mostraram ansiosos e apreensivos, comentando entre si como seria, afinal, esta aula.

Conforme combinado, no dia 16 de dezembro iniciamos as atividades com uma explicação. Esta ação seguiu o conceito de direcionamento da linha de raciocínio dos alunos: o quadro-negro foi dividido em duas partes e as palavras "Tempo" e "Espaço" foram escritas. Os alunos acompanharam esse procedimento em silêncio. Na sequência foram entregues quatro folhas de sulfite para que expressassem suas ideias sobre esses conceitos. Foi solicitado que colocassem nas folhas seus pensamentos, lembranças, imagens etc., ou seja, o que viesse a mente sobre tempo e espaço.

Aos alunos foram dadas alternativas para essa descrição: poderiam fazê-la por meio de imagens (desenhos e formas), frases soltas ou de um texto mais minucioso. O importante era o 
registro do seu conhecimento sobre os temas "Tempo" e "Espaço". Durante a explicação inicial os alunos permaneceram em silêncio e assim ficaram por mais alguns minutos. Preocupada com essa atitude por parte dos alunos incitei a iniciarem a atividade através de questionamentos provocativos. Ainda assim houve resistência.

Por um momento, imaginei que eles não realizariam tal tarefa. $\mathrm{Na}$ quietude da sala, observei que muitos estavam distantes em pensamentos, seus olhares eram fixos no vazio e muitos deles com a mão apoiadas no queixo, o que causava a ideia de dúvidas, incertezas. Como se perguntassem silenciosamente: e agora, o que vou fazer? Ao perceber isto, tentei incentivá-los a começar a tarefa: "vamos pessoal, não é difícil. É só vocês dizerem o que sabem/conhecem por espaçol tempo. O que significa para você? Podem faz̧er o que sabem! Eu só quero que comentem textualmente e façam figuras sobre estas duas palavras". Na perspectiva de professora de física e matemática, certamente tal atividade não era difícil, mas por um momento foi esquecido que os alunos poderiam não dominar alguns dos conhecimentos específicos desta área (como a nomenclatura e suas especificidades). Essa fala foi repensada para a atividade seguinte.

Após muitos incentivos, começaram a fazer a atividade. Passado algum tempo entregaram o que tinham feito. Porém, foi observado que os alunos demonstraram durante todo o processo a preocupação em fazer tudo errado e mesmo diante das suas falas ainda se fazia incompreensível o fato de estarem utilizando apenas duas folhas, quando haviam sido entregues quatro folhas (duas para Tempo e duas para Espaço).

No dia seguinte começamos a aula com uma rodada de perguntas: "qual foi a dificuldade que vocês encontraram para realizar a atividade de ontem?" Como os alunos ainda estavam confusos acerca do trabalho proposto, houve inquietação com relação ao desenvolvimento da atividade, pois, mesmo após inúmeras explicações eles continuavam sem entender o que haviam feito e entregue.

Com relação à questão de Tempo e Espaço questionou-se: "E o que é tempo e espaço para vocês??". Os alunos indígenas consideram que esses dois elementos estão inseridos num mesmo contexto e que, desta forma, são inseparáveis. Para efeito de comparação, na mecânica newtoniana tais elementos não são intrínsecos um ao outro, ao contrário, são conceitos distintos.

Foi perguntado aos alunos porque não utilizaram as quatro folhas, conforme solicitado, mas apenas duas. Responderam que para eles tempo e espaço estão inseridos no mesmo contexto, que estão intimamente ligados, portanto, não podem ser separados. Desta forma, foi possível entender porque não haviam utilizado as quatro folhas. Assim, por meio dessa atividade foi possível compreender algumas narrativas orais feitas pelos alunos: a questão ambiental; a sobrevivência (em relação à aldeia enquanto lugar demarcado geograficamente, a mata, roça); o cosmológico (universo e o sistema solar) e o conhecimento (escola e família).

Isto posto, quando é perguntada à aluna 12 qual é o seu nome ela o diz seguido do apelido, como se esse fizesse parte do seu primeiro nome. Na cultura indígena o uso do apelido é considerado importante na substituição do primeiro nome. Conforme explica Meliá:

O nome pode estar tão ligado à personalidade que, qualquer mudança significativa na vida da pessoa - ato de bravura heroica, saída de uma doença grave -, pode motivar e até obrigar a uma mudança de nome. Mudar de nome ou acrescentar durante a vida vários nomes, marca de prestígio social e religioso. (MELIÁ, 1979, p. 22). 
O título dado ao texto desta aluna é "tempo no espaço". Quando a aluna se refere ao seu tempo de infância faz referência ao tempo que possuía e ao espaço para brincar, como se tempo e espaço fossem um só elemento. A aluna apresenta o tempo ligado ao clima e o divide em verão e inverno, sendo o primeiro voltado para as brincadeiras infantis e o segundo para o descanso sob os cobertores. Considera como "tempo bom" aquele em que não houvesse chuvas, pois era quando saia para brincar. Já adulta, o tempo é voltado aos estudos e a busca por um futuro melhor para a família. Percebe-se que os objetivos indígenas são substituídos pelos objetivos dos não indígenas, ou seja, a busca constante por um futuro considerado melhor que o presente.

A aluna 09 apresentou seu texto sobre tempo e espaço em forma de poesia, observando que o saber é mais do que querer criar ou saber dizer, é saber fazer baseado em conhecimentos acumulados no decorrer da vida (LUCIANO, 2006):

\section{TEMPO}

Nois mulher precisa de tempo para lavar roupa e cozinha.

O bebe precisa de tempo para nascer o dente.

Sempre vamos precisa do tempo para estudar e tomar banho, e ir no Banco.

Tem tempo de nascer

Banana e milho e mandioca.

Tempo ir na balada.

Tempo de namorar.

Nois tem tempo de feria.

O tempo de envelhecer.

Nois temos tempo de ser feliz,

O tempo de casar e ter filhos.

O tempo de sofrer.

O tempo de colheita.

\section{ESPAÇO}

Para ir na cidade tem que ter espaço. Espaço para dançar.

Eu preciso de espaço para jogar bola.

O espaço da palavra vazia e doce.

Espaços tem que ter em cada um da planta.

Espaços e uma coisa que não podem tirar das pessoas que trabalha.

Espacos nois tem que ter para morar familia.

Espacos tem que ter para os animais.

Para esta aluna o tempo está diretamente relacionado à realização dos afazeres domésticos, no desenvolvimento do ser humano e das plantas. O tempo também é utilizado enquanto tempo cronológico quando se refere às horas destinadas à diversão e ao sofrimento. Com relação ao espaço, a aluna aparentemente se confunde ao relacionar momentos de descontração e ao mesmo tempo, afirma que existe "o espaço da palavra vaz̧ia e doce". Este espaço pode ser prazeroso e, simultaneamente, é como se faltasse algo. Desta forma, a aluna utiliza expressões abstratas e/ou subjetivas para descrever sua percepção sobre espaço. Também apresenta o espaço de acordo com seu significado ao citar sua presença entre uma planta e outra ou ainda quando se refere ao lugar em que a família deve morar e onde os animais devem ficar. 
Para aluna 04 o espaço é um lugar que pode ser construído por nós: como a casa, a horta, o pomar, etc. Já o tempo está ligado à presença dos entes queridos e à lembrança dos momentos vividos ao lado da família.

Para a aluna 02 o tempo está relacionado ao tempo cronológico e também ao espaço, pois cita as divisões de horas para determinadas atividades do cotidiano, como os afazeres domésticos, a diversão, os estudos e o plantio da roça. Para plantar também é preciso espaço, ou seja, tempo e espaço não se separam como pode ser visto no texto da Figura 1.

Figura 1. Produção textual da aluna 02

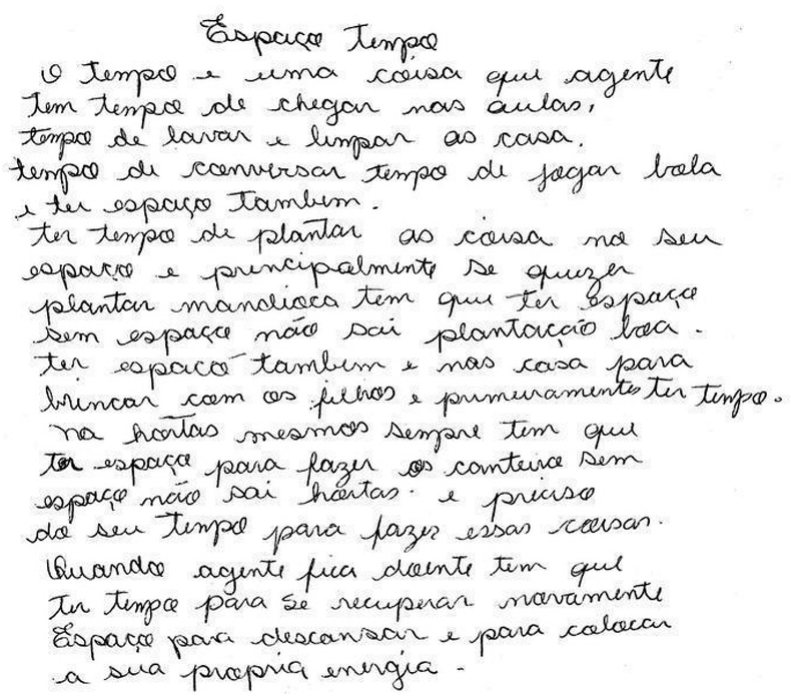

Fonte: texto elaborado por aluna.

A aluna 06 associa espaço e tempo aos obstáculos e dificuldades do cotidiano na aldeia:

O espaço tempo é muitas coisas que acontecem aqui na aldeia muita violência, morte, assalto, drogas, bebidas alcoólicas, estupro das crianças daqui da aldeia vai dormir na rua tem pessoa que não tem casa pra morra quando os (pais) das criancas recebe se compra bebida alcoólica é por isso muitas crianças foram pedi as coisas na rua as bebidas alcoólicas, fica bêbado não cuida dos filhos é por isso o conselbo [tutelar] tira da mãe as vezes não tem comida para comer.

Para o aluno 10 a noção de tempo está relacionada com o tempo cronológico, pois no seu texto ele fala sobre sua infância e as maneiras de brincar, já no desenho ele retoma a situação em forma de espaço, reforçando o paralelo entre espaço e tempo. Explica-se a relação 
entre esses dois conceitos de maneira clara e objetiva quando a fala dos alunos foi proferida na atividade pré-teste em que esses dois conceitos não se separavam.

As concepções de tempo apresentadas pelos alunos indígenas são semelhantes às levantadas por Ramos e Scarinci (2013), a saber:

\section{Tempo}

a) tempo relacionado com o clima, com fenômenos climáticos;

b) tempo como algo necessário para realizar uma atividade, como algo que pode demorar a passar, que traz felicidade ou tristeza e relacionado com o cotidiano;

c) tempo relacionado com o relógio, medido através dos dias, horas minutos e segundos.

Já para o conceito de espaço, das quatro categorias levantadas por Ramos e Scarinci (2013, p. 20), apenas a categoria (b) se aproxima da fala dos alunos indígenas: "Espaço que ocupamos ou necessitamos para fazer algo e onde podemos construir ou guardar nossas coisas, como o espaço para construir uma casa, o espaço de um armário”.

A partir desta relação com a pesquisa de Ramos e Scarinci, evidencia-se questão a ser investigada com maior profundidade em estudo posterior: opapel das diferenças culturais na construção dos conceitos de tempo e espaço por alunos indígenas e não indígenas.

\section{Segunda Atividade: Conceitos de Espaço e Tempo}

A segunda atividade, a construção de um relógio de Sol, foi realizada no tempo comunidade (TC). Dentro do Projovem Campo existe o momento em que os alunos saem da sala de aula para aulas práticas relacionadas com o tempo escola (TE), que são as aulas ministradas dentro da instituição escolar. A atividade foi realizada com 13 alunos.

A atividade seguiu a sequência: (a) foi solicitado aos alunos que encontrassem um lugar para marcar o chão com um círculo; (b) em seguida deveriam colocar uma vareta no centro deste círculo e então medir o espaço entre a vareta e a borda do círculo, sem auxílio de instrumentos não indígenas e, por último, (c) deveriam registrar a sombra do Sol sobre a vareta, observando o espaçamento e a margem do círculo. Foi solicitado aos alunos que descrevessem os recursos e métodos utilizados, a especificação das medidas, justificativa da escolha e se tal medida é/foi utilizada no dia a dia do indígena.

A construção de um relógio do Sol é importante para a percepção dos alunos com relação à valorização de recursos distintos dos aparatos tecnológicos que são oferecidos hoje (AZEVEDO et al., 2013; MARTINS; ZANETIC, 2008). Além do Sol, eles também lançaram mão do canto do galo para a identificação das horas. A marcação do tempo pelos ciclos da Lua também é utilizada tanto no plantio como na pesca e caça. A Lua Cheia determina as atividades que podem ser realizadas e aquelas que são proibidas.

Com relação aos recursos utilizados podemos perceber que dos 13 alunos, 10 utilizaram a própria mão (do dedo polegar ao mínimo) para executar a medição e outros usaram meios diversificados como os pés e pequenas raízes de árvore. Como não havia outro tipo de recurso, já que foram proibidos instrumentos como régua, metro, trena, etc., para esta medida, 
recorreram a outras estratégias de medição que entenderam ser mais práticas e usadas por seus avós. Estes dividiam as formas de medição de acordo com o tamanho do que deveria ser medido, sendo que para espaços menores a medida era feita com as mãos (Figura 2) e para espaços considerados maiores eram utilizados os pés (Figura 3). Um dos alunos que utilizou as mãos como recurso de medição usou o argumento a seguir para justificar sua escolha: "Eu escolhi a minha mão porque fica melhor para eu entender a minha medida e ajuda a medir mais rápido" (Aluno 05).

Figura 2. Detalhe de aluna fazendo a medição da sombra no relógio de Sol

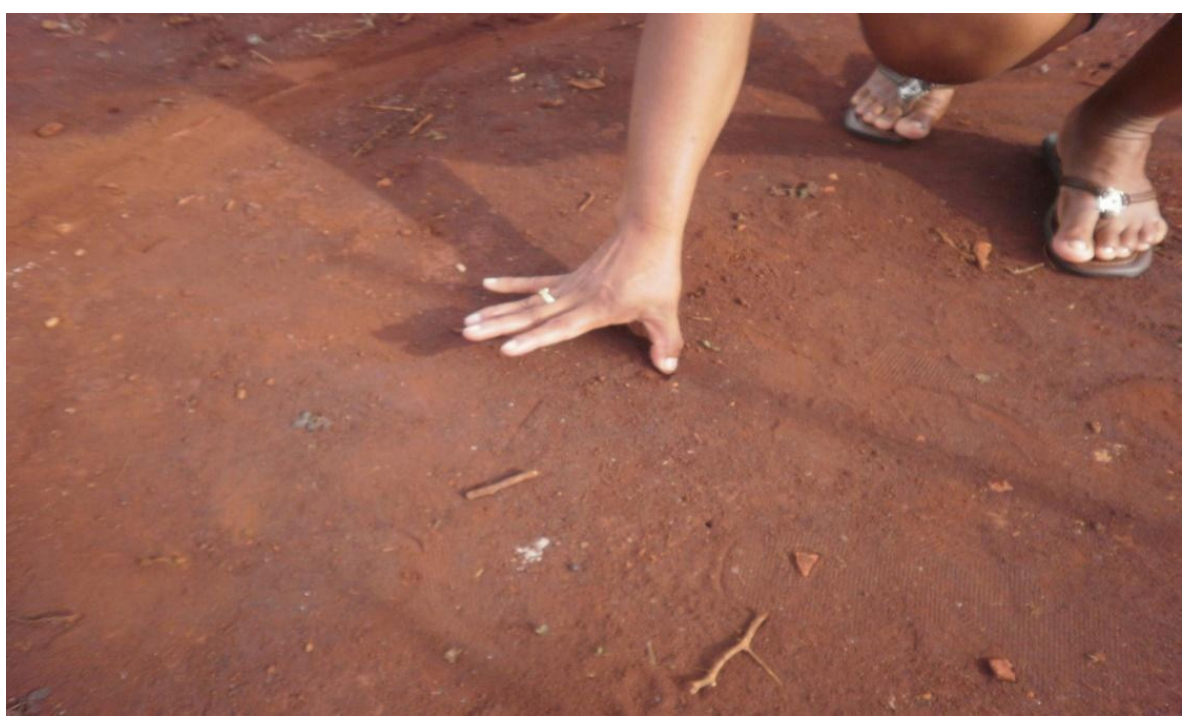

Fonte: arquivo dos autores.

As medições foram feitas entre três e seis vezes ao dia, podendo ser nesse caso, três vezes pela manhã e três vezes durante a tarde. Esse foi o procedimento seguido pelo aluno 12, que iniciou suas medidas pela manhã e as encerrou no final da tarde:

Eu encontrei a medida durante a atividade, a primeiramente foi vinte espaços, a sombra da vareta, depois pouco tempo den cinco espaços a sombra da vareta, pouco depois en fui contar de novo deu quatro espaços a sombra da vareta, uma da tarde deu quatro espacos de novo a sombra da vareta, duas da tarde deu a sombra da vareta deu oito espacos, quatro horas da tarde en fui medir, deu vinte espaços a sombra da vareta deu de novo. [ aluno 12]. melhor".

Já o aluno 04 afirmou "Eu escolbi o péporque fica mais fácil e mais prático e assim eu entendo 
Figura 3. Detalhe de aluna fazendo a medição da sombra no relógio de Sol

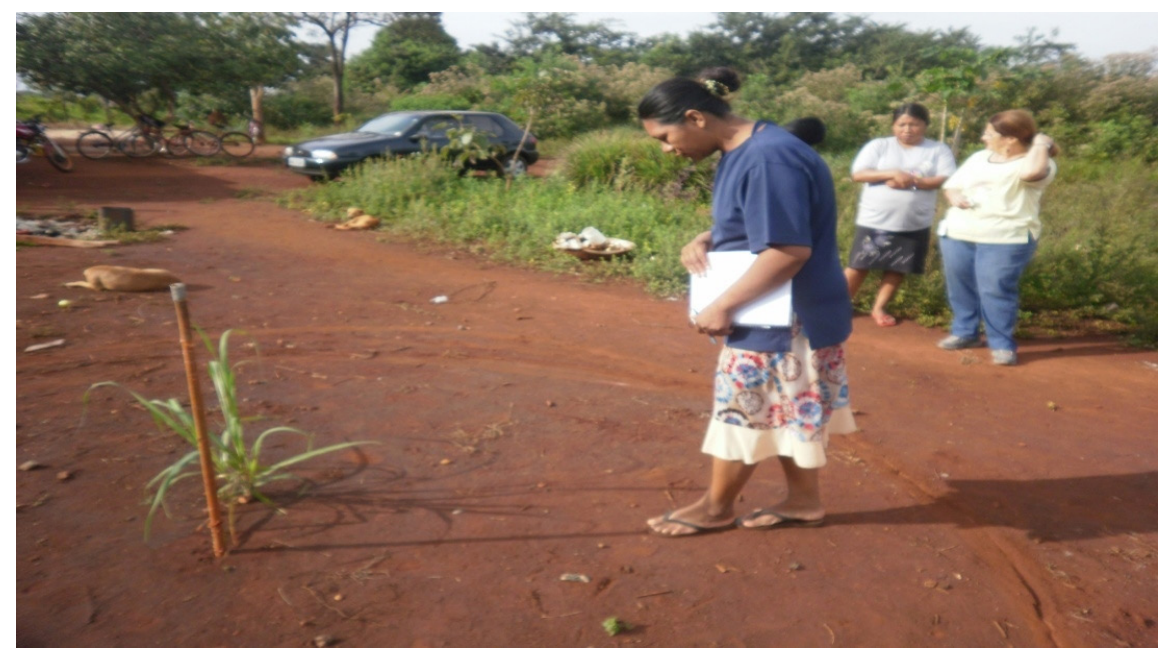

Fonte: arquivo dos autores.

A justificativa para escolha do recurso e do método está pautada na praticidade e na facilidade da compreensão da atividade e de seus significados para cada indivíduo. Este fato é evidenciado pela fala do aluno 12 quando este explica o porquê da sua opção: “Eu escolhi para medir com meu pé, porque é fácil para medir com pé, porque conto mais rápido com o pé” [aluno 12].

Já o aluno 01 afirma que a escolha foi baseada no conhecimento de seus antepassados: "Eu escolbi essa maneira de medir para nós é muito importante antigamente nós indio media com nossa sombra para saber hora do espaço e tempo" [aluno 1].

A medição no cotidiano dos indígenas aparece, principalmente, no plantio das roças e na construção de suas casas. Podemos observar isso nas seguintes falas:

Quando eu começo a plantar mandioca a minha medida eu uso o passo e duas ramas a cada buraco para sair uma boa plantação, e também a cada semente do milho não podia cair muitos no buraco. [Aluno 2].

A medida que nos usa no dia a dia usava a sombra das árvores, sombra da casa que um dia minha avó falava que no tempo do frio não dá nada para plantar. [Aluno 5].

Minha avó falou a medida de plantação primeiro tem que olha na lua se for a lua nova não é para plantar e bom plantar só na lua cheia para plantar precisa usar medida, mas tem que se usar no paço é a medida certa. [Aluno 8].

Com relação à utilização dessas escolhas no dia a dia do indígena, foi possível perceber que tais medidas são rotineiras. Essas estratégias de medição são utilizadas desde a construção de uma casa quanto para o espaçamento no plantio de sementes e ramas na roça, além de ser 
um método eficiente para identificação da hora. O aluno 11 descreve em sua fala o uso do espaço e do tempo apresentado por sua avó e, ao mesmo tempo, dá sua opinião sobre o tema trabalhado nas atividades propostas:

A medida dela [da avó] era sombra da casa, também sombra da árvore, pra ela conhecer a hora. Antigamente não tinha relógio, as pessoas não usava celular - as pessoas usava mais medida dos pés usava - a mão para medir os espaços. Também antigamente plantava no dia chuvoso para planta sair rápido, pessoa de antes plantava quando lua estivesse bom. Pessoa de hoje medi na metragem, medi com régua dia de hoje não medi mais com a mão precisa mais com metro. Também já usa celular, relógio, computador, rádio para ele saber o horário de saída, mais antepassado não. A minha mãe sempre tinha contado a história dela pra nós - sobre da caça mais melhor é depois da chuva e tatu sai para comer fungos, também men pai tinha falado quando comesa esfriar, cobra entra no buraco não sai mais de lá - principalmente o lagarto. [aluno 11].

Foi possível observar que as medições do espaço e tempo através de estratégias tradicionais ainda se fazem presente em suas vidas, apesar de muitos indígenas não valorizarem estes conhecimentos. Embora muitos digam que não praticam mais os conhecimentos tradicionais, quando solicitado que narrem relatos/histórias sobre situações em que seus antepassados, e até mesmo em que eles próprios são os protagonistas deste conhecimento, todos participam e se lembram de fatos marcantes em suas vidas. Desta forma, todo conhecimento tradicional que possa ser trazido para reflexão na escola junto com o conhecimento científico contribui para uma compreensão ampliada e ressignificada desses conhecimentos para os alunos indígenas.

\section{Considerações finais}

Através da oralidade o aluno indígena passa por uma educação diferenciada (em comparação às nossas concepções não indígenas) no que se refere aos ensinamentos que são transmitidos de pais para filhos, enquanto a educação escolar indígena, regida pela legislação vigente, visa uma educação pautada mais no ensino regular do que na educação do aluno indígena. Disto surge uma questão para reflexão: que benefício isso traz para esse aluno?

Entendemos que os alunos que chegam à escola são sujeitos socioculturais, com um saber, uma cultura e também com projetos mais ou menos conscientes, fruto das experiências vivenciadas dentro do campo de possibilidades de cada um. A escola é, portanto, parte do projeto dos alunos.

Das lutas pela preservação de sua cultura e da problemática de contato com não índio surgem preocupações sobre (a) questões curriculares e metodológicas que marcam a discussão sobre os conteúdos, (b) métodos utilizados na educação escolar indígena bem como o acesso, em qualidade e igualdade, à continuidade dos estudos no ensino regular e (c) instrumental necessário para busca de soluções dos problemas do contato e interação do índio com a sociedade não indígena. Neste sentido, a formação continuada de professores em regiões de forte presença indígena deve ser planejada e executada de forma a prepará-los minimamente para os desafios e obstáculos particulares que encontrarão em sala de aula. 
Com a discussão apresentada neste trabalho espera-se contribuir para o reconhecimento da importância destes saberes que, embora não possam ser sistematizados na mesma perspectiva metodológica do pensamento científico contemporâneo (dada a incomensurabilidade entre ambos os sistemas de conhecimento), envolvem conhecimentos práticos que representam respostas humanas criativas aos problemas enfrentados pelos grupos indígenas em seu processo de desenvolvimento histórico-sociocultural.

Se concebermos que o aluno pode desenvolver seu espírito crítico analisando e construindo suas conclusões, então acreditamos que podemos apenas ajudá-lo a pensar, pois, se ao contrário, se ensinarmos que o aluno deve se "encaixar" e pensar dentro dos métodos prontos e acabados, estaremos impedindo-o de procurar pelo desconhecido.

Assim, através das leituras feitas para a elaboração deste trabalho e para as atividades de campo que foram realizadas percebi que os alunos indígenas têm conceitos e saberes próprios e que a falta de motivação para irem até a escola ocorre por motivos diversos. Esses motivos passam, em alguns casos, pela questão da violência, da falta de um elo entre a educação e a realidade indígena e da falta de perspectiva.

Aspecto relevante a ser considerado é quanto a dificuldade de obtermos material teórico e metodológico para trabalhar o ensino de ciências e física com alunos indígenas. Praticamente todos os materiais que encontramos para trabalhar estas matérias com os alunos não levam em consideração as especificidades étnicas.

Entendemos que outro referencial para o ensino desta disciplina é possível, em especial, mas não apenas, quando se trata dos conceitos de espaço e tempo para alunos indígenas, já que devem ter respeitados seus conhecimentos e saberes. É necessário levar em consideração que a educação para os povos indígenas não se realiza em uma única instituição, mas pela ação e pelo envolvimento de toda a comunidade. Essa educação ocorre em tempos e espaços cotidianos, por meio de pedagogias próprias e diversas que garantem tanto a reprodução quanto a recriação da identidade, da tradição, dos saberes, dos valores, dos padrões de comportamento e de relacionamento.

Desta maneira, através da pesquisa de campo, a atividade de pré-teste revelou a falta de conhecimento científico, no entanto na descrição por meio dos desenhos e das produções textuais foi possível perceber que os alunos indígenas apresentaram um modelo que descreve/ conceitua espaço e tempo. Na segunda atividade puderam aplicar modelos na prática, utilizando recursos que seus antepassados teriam usado para efetuar a mesma ação.

Portanto, como educadora de alunos indígenas e não indígenas, foi perceptível a diferença do processo da construção de conhecimento sobre tempo e espaço. Fica evidente que o ensino dessas duas modalidades deve acontecer também de forma diferente nos dois tipos de educação - Educação Indígena e não Indígena.

Por fim, considerando os resultados obtidos neste trabalho realizamos a seguinte sugestão para futuras pesquisas: levantamento de maiores informações sociais sobre futuros grupos de alunos, tanto em relação ao convívio dos diferentes agrupamentos indígenas (guarani e kaiowá) forçosamente obrigados a morarem em uma mesma área, quanto (b) a especificidade do contato interétnico, isto é, entre a população indígena e a comunidade branca. Estas duas dimensões certamente interferem no ensino e na aprendizagem. 


\section{Referências}

ÂNGELO, F. N. P. Políticas educacionais com os povos indígenas. In: RAMOS, M. N.; ADÃO, J. M.; BARROS, G. M. N. (Ed.). Diversidade na educação: reflexões e experiências. Brasília: Secretaria de Educação Média e Tecnológica, 2003.

AZEVEDO, S. S. M. et al. Relógio de sol com interação humana: uma poderosa ferramenta educacional. Revista Brasileira de Ensino de Física, São Paulo, v. 35, n. 2, p. 2403, 2013.

BRASIL. Ministério da Educação. Referencial curricular nacional para as escolas indígenas. Brasília, 1998.

FLICK, U. Desenho da pesquisa qualitativa. Porto Alegre: Bookman, 2009a.

Introdução à pesquisa qualitativa. Porto Alegre: Bookman, 2009b.

IBIAPINA, I. M. L. M. Pesquisa colaborativa: investigação, formação e produção de conhecimento. Brasília: Liber, 2008.

LUCIANO, G. S. O índio brasileiro: o que você precisa saber sobre os povos indígenas no Brasil de hoje. Brasília: Ministério de Educação, 2006.

LÜDKE, M.; ANDRÉ, M. E. D. A. Pesquisa em educação: abordagens Qualitativas. São Paulo: EPU, 2008.

LUNA, S. V. O falso conflito entre tendências metodológicas. Cadernos de Pesquisa, São Paulo, n. 66, p. 70-74, 1988.

MARTINS, A.; ZANETIC, J. O tempo na mecânica: de coadjuvante a protagonista.

Caderno Brasileiro de Ensino de Física, São Paulo, v. 19, n. 2, p. 149, 2008.

MARTINS, H. H. T. S. Metodologia qualitativa de pesquisa. Educação e Pesquisa, São Paulo, v. 30, n. 2, p. 289-300, ago. 2004.

MELIÁ, B. Educação indígena e alfabetização. São Paulo: Edições Loyola, 1979.

OLIVEIRA, M. M. Como fazer pesquisa qualitativa. Petrópolis: Vozes, 2007.

RAMOS, T. A.; SCARINCI, A. L. Análise de concepções de tempo e espaço entre estudantes do ensino médio, segundo a epistemologia de Gaston Bachelard. Revista Brasileira de Pesquisa em Educação em Ciências, Belo Horizonte, v. 13, n. 2, p. 009-025, 2013.

SECRETARIA MUNICIPAL DE EDUCAÇÃO. Diagnóstico situacional das aldeias indígenas de Dourados - MS (2011/2012). Dourados: Prefeitura Municipal de Dourados, 2011.

TRIVIÑOS, A. N. S. Introdução à pesquisa em ciências sociais: a pesquisa qualitativa em educação. São Paulo: Atlas, 1987.

VARGAS, V. L. F. A construção do território Terena (1870-1966): Uma sociedade entre a imposição e a opção. Dissertação apresentada ao Programa de Pós-Graduação em História Dourados: UFMS, 2003. 
Oliveira, R. A. N.; Ferreira, F. C.

Artigo recebido em 20/09/2016. Aceito em 14/12/2016.

Endereço para contato: UFGD, Faculdade de Ciências Exatas e Tecnologia, 79804-970, Dourados, MS, Brasil. 